\title{
COVID-19 Pandemic and Pre-Participation Evaluations: Risks and Precautions
}

\section{COVID-19 Pandemisi ve Spora Katılım Öncesi Değerlendirmeleri: Riskler ve Önlemler}

\author{
Burkay Utku' ${ }^{1}$, Erdem Kaşıkçıoğlu ${ }^{2}$ \\ ${ }^{1}$ Sports Medicine Section, Physical Therapy and Rehabilitation Hospital, Ankara City Hospitals, Turkey \\ ${ }^{2}$ Cardiofit Health Service, Redbridge Trust, London, United Kingdom
}

B. Utku

0000-0002-6423-723X

E. Kaşıkçığlu

0000-0003-1855-7088

Geliş Tarihi/Date Received: 10.06.2020

Kabul Tarihi/Date Accepted: 10.06.2020

Yayın Tarihi/Published Online: 16.07.2020

\section{Yazıșma Adresi /}

Corresponding Author:

Burkay Utku

Ankara Şehir Hastanesi, Fizik

Tedavi ve Rehabilitasyon

Hastanesi, Spor Hekimliği

Bölümü Ankara, Turkey

E-mail:

burkay.utku@gmail.com

(C)2020 Türkiye Spor Hekimleri Derneği. Tüm hakları saklıdır.

\begin{abstract}
Many sports organizations are paused all over the world according to COVID-19 pandemia precautions. As COVID-19 pandemic is going on, it has become a necessity to review the health screening applied as routine while assessing the eligibility of the athletes participating in competetive sports. A detailed expert opinion is prepared for sports pre-participation examinations with consideration of the cardiac involvement observed in the course of COVID-19.

Keywords: COVID-19, pre-participation examinations, myocarditis
\end{abstract}

ÖZ

COVID-19 pandemisi tedbirleri kapsamında tüm dünyada birçok spor organizasyonlarına ara verilmiştir. COVID-19 pandemisi devam ederken yarışmalı sportif aktivitelere katılacak sporcunun uygunluk değerlendirmesini yaparken daha önce rutin olarak uygulanmakta olan sağlık taramalarının tekrar gözden geçirilmesi bir gereklilik haline gelmiştir. COVID-19 enfeksiyonu sırasında kardiyak tutulumun gösterilmiş olması da göz önüne alınarak spora katıım öncesi sağlık değerlendirmeleri için ayrıntılı bir uzman görüşü hazırlanmıştır.

Anahtar sözcükler: COVID-19, spora katılım öncesi değerlendirmeleri, miyokardit

Available at: http://journalofsportsmedicine.org and http://dx.doi.org/10.5152/tjsm.2020.198

Cite this article as: Utku B, Kasikcioglu E. COVID-19 pandemic and pre-participation evaluations: Risks and precautions. Turk J Sports Med. 2020;55(3):251-55.

Dünya Sağlık Örgütü tarafından Koronavirüs (COVID-19) endemisinin pandemi olarak kabul edilişinden bu yana radikal olarak tanımlanabilecek düzeylerde değişiklikler yaşanmaya devam etmektedir. Etkinliği ve etkileri tahmin edilemeyen pandeminin bir süre daha devam edeceği düșünülürken, insanoğlunun en çok etkilenen konak ve kitlesel bulaștırıcı vektör olması nedeniyle, kişisel mesafenin ortadan kalktığ 1 ve insan 
gruplarının bir araya geldiği etkinliklere yeniden bakış koruyucu hekimlik adına daha önemli hale gelmiştir. En fazla üzerinde durulan kitlesel etkinlikler spor aktiviteleridir. "Pandeminin etkileri yaşanmaya devam ederken spor aktiviteleri sporcu ve toplum sağlığı göz önüne alınarak nasıl organize edilmeli?" sorusu, bilimsel kanıtların eşliğinde yanıt beklemektedir. Salgın sürecinin başlangıcında, birçok ülkede tartışmalar eşliğinde ilk alınan önlemlerden biri bulaş riskini azaltmak için her türlü spor organizasyonuna ara vermek olmuştur. Bir yandan da salgının etkisini azaltması beklenirken, birçok spor branşında yeni sezon programları yapılmaya başlanmıştır. Bilindiği üzere, resmi yarıșmalara katılabilmeleri için sporcuların spor hekimliği kliniklerinde veya diğer sağlık birimlerinde spora katılım öncesi muayenelerinin yapılması ve katılımı uygun görülenlerin lisans raporu almaları gerekmektedir. COVID-19 pandemisi sürerken spora katılım öncesi değerlendirmelerde kullanılan yöntemlerin yeniden gözden geçirilmesi uygun olacaktır. İlgili yönetmelikler gereği, ülkemizde lisanslı sporcu olabilmek için öncelikle spora katılımda sakınca bulunmadığına dair bir sağlık raporu alınması gerekmektedir. Bu raporu düzenlerken izlenen kılavuzlar bulunmaktadır. Avrupa Spor Hekimleri Derneği Avrupa Kardiyoloji Derneği'nin önerilerini referans alarak 2015 yllında bir kllavuz yayınlamıștır. Buna göre; ayrıntılı bir tıbbi öykünün alınması, genel sistem muayenelerinin yapılması ve 12 derivasyonlu dinlenim EKG'sinin kaydedilmesi ve değerlendirilmesi önerilmektedir (1). Bu değerlendirmelerde anormal bir bulgu saptanırsa, ileri tetkik ve incelemelerin yapılması önerilmektedir.

COVID-19 ileri yaşlardaki bireyler için yüksek riskli kabul edilmesine karşın, her yaştan sporcuyu etkileyebileceği ileri sürülmektedir. Hastalığın ciddi klinik bulguların görüldüğü tabloya dönüştüğü bireylerin çoğunda yüksek oranda ölümcül olabilen akut solunum sıkıntısı sendromuna (Acute Respiratory Distress Syndrome, ARDS) yol açabildiği bilinmektedir. Bunun dışında, hastaların klinik seyir ve prognozunu değiștiren diğer önemli unsurun kardiyo- vasküler sistemin değişik derecelerde etkilenmesi olduğu gösterilmiştir (2). Ayrıca, inflamatuvar yanıtın göstergelerinden olan yüksek IL6 , serum ferritin ve kardiyak troponin değerleri, vücutta başlamış olan sitokin firtınası ve diger immünolojik faktörler devam eden hastalığın risk ve prognoz belirteçleri olmasının yanı sıra, kötü prognoz göstergesi olan kardiyovasküler tutulumun da parametreleri olduğu kabul edilmektedir (3). Klinik sürecin azımsanmayacak boyuttaki olgularda çoklu organ yetersizliğine dönüșebildiği ileri sürülmektedir. 1527 hastanın verilerinin değerlendirildiği bir meta-analizde olguların yaklaşık \%8`inde kardiyak hasarın oluştuğu saptanmıştır (4). COVID-19 nedeniyle yaşamını yitiren olguların otopsi çalışmasında miyokarda intertisyel mononükleer infiltrasyonun geliştiği ortaya konmuştur (3).

Konuyla doğrudan ilișkili verilerin yetersiz olmasına karşın, sporcu grubunda bu hastalığa yakalananların çoğunun hastalığı ya asemptomatik olarak ya da hafif bulgular ile geçireceği tahmin edilmektedir (5). Bu olumlu öngörüye rağmen, COVID-19'da solunum sistemi dışında kardiyovasküler sistemin ikinci en çok etkilenen sistem olduğunun ortaya konmasiyla birlikte, hastalığa yakalanan sporcu asemptomatik olsa bile sinsi seyirli bir miyokardit patolojisi olasılığı hesaba katılmalıdır. Sporcuların sağlık değerlendirmeleri yapılırken olası miyokarditi gözden kaçırmamak adına bulgu ve belirteçler titizlikle kaydedilmelidir (6).

Sporcularda görülebilen miyokardit olgularında dinlenim kalp hızı artışı, çarpıntı, yorgunluk ve halsizlik, egzersiz intoleransı gibi bulguların değişken yoğunluklarda, hatta belli belirsiz bir semptomatolojiyle gidebildiğini hatırlamak, doğru tanının konulabilmesi için kritiktir. COVID-19 ile birlikte silik semptomatolojiyle seyretme olasılığı olan miyokardit olgularının mikrobiyolojik, serolojik ve enzimatik testlerinin yapılmamasına bağlı olarak atlanabileceği varsayılmaktadır $(2,5,6)$. Hafif klinik semptomlarla başvuran sporcu olmayan olguların literatürde paylaşılmış olması, sporcu grubunun da benzer şekilde etkilenebileceğine işaret etmektedir (7). Daha önce yayınlanmış 
bilimsel kanıtlar temel alındığında, miyokardite bağlı ani ölümlerin 35 yaş altı sporcularda görülebildiğini düşünürsek, COVID-19 semptomları olan veya hastalığı geçirdiği tanısal olarak ortaya konan sporcularda ayrıntılı bir kardiyak değerlendirmenin önemi daha da net bir şekilde ortaya çıkmaktadır (8). COVID-19 enfeksiyonuna bağlı kardiyak tutulumla ilişkili olmasa bile, solunum sistemi hasarına bağlı hipoksi, hemodinamik değişiklikler ve tedavide kullanılan ilaçların istenmeyen etkilerine nedeniyle ortaya çıkabilecek ciddi aritmi riskini de unutmamak gerekir $(3,9)$.

Bahsettiğimiz gerekçelerle, sporculara ait ulusal izlem takip parametrelerinin oluşturulmasının klinik pratik açısından kolaylaştırıcı olacağını düşünmekteyiz. Son zamanlarda, konuyla ilişkili değişik kaynaklarda kısa notlar şeklinde öneri taslakları ortaya konmuştur. Yeni bilimsel verilerle değișeceğini düşündügümüz bu şemaları klinik pratik ve yaklaşımlarımızın tutarlılık, güvenilirlik, tekrarlılık temelinde güncellenebilirliğini kolaylaştırmak adına tartışmaya açmanın ve ulusal şablonları şimdiden kullanmanın yerinde bir yaklaşım olacağı kanaatindeyiz. Öncelikle başvuruda bulunan sporcunun semptomatik olup olmadığını kaydetmek gerekir. Sporcu, şikayetleri arasında belirtmemiş olsa bile, hafif seyirli bir miyokardit olabileceği düşüncesiyle detaylı sorgulama yapılmalıdır. Temel değerlendirme kılavuzlarında belirtildiği şekilde anamnez, sistemik muayene ve 12-derivasyonlu EKG incelemesini mutlaka tamamlamak gerekir. Sistemik muayene ve EKG'de anormal bulgular varsa hem COVID-19 açısından hem de diğer hastalıklar açısından ileri inceleme ve değerlendirmenin yapılması yerinde olacaktır.

Asemptomatik olarak değerlendirilen her sporcuda da, test sonucuna bakılmaksızın mutlaka eş zamanlı olarak ateş ölçümü ve istirahat nabız değerleri kaydedilmelidir. Herhangi bir nabız diskordansının ortaya konulması, olası tanı açısından bir ipucu niteliğinde olabilir. Asemptomatik sporcuda COVID-19 testi pozi- tifse, virüsün maksimum inkübasyon süresi dikkate alınarak, 14 gün süreyle sporcunun izlenmesi gerekir. Bu süre içinde herhangi bir semptom ortaya çıkmamışsa, diğer standart değerlendirmeler tamamlandıktan sonra spora dönüş izni verilebilir (Şekil 1). Diğer taraftan semptomatik olmasına rağmen testi negatif olan sporcuların spora uygunluk değerlendirmeleri, sporcunun tüm semptomları tamamen ortadan kalkmadan yapılmamalıdır (Şekil 2). Yapılacak değerlendirme içinde, en kritik unsur miyokardit tanı olasılığının titizlikle araştırılması olmalıdır. Ekokardiyografideki en ufak bir duvar hareket bozukluğunu miyokardit lehine yorumlamak sporcunun sağlığının korunması açısından yanlış bir yaklaşım olmayacaktır. Benzer anormal klinik-laboratuvar bulgularının varlığı, testi pozitif semptomatik sporcularda miyokardit tanı olasılığını daha fazla destekler nitelikte olmalıdır. Kardiyak enzim yüksekliğinin hastalığın şiddet ve evresiyle değişkenlik gösterebileceği bilinmekle birlikte, troponin düzeyinin normale dönmüş olması durumunda bile miyokard hassasiyetinin bir süre daha devam edebileceği unutulmamalıdır. $\mathrm{Bu}$ nedenle, hastalığın seyrinde gelişebilecek klinik riskler açısından sporcuların titizlikle izlenmeleri gerekir.

Bütün bunların dışında, orta ve ağır şiddette COVID-19 enfeksiyonu tedavisinde önerilen ve kullanılan steroid, antibiyotikler, antimalaryal ilaçlar, immünosüpresanlar ve antiviral ilaçların kardiyak ileti sistemini etkileyerek ciddi aritmilere ve hatta bazen ani ölümlere yol açabileceği kabul edilmekte, sporcu hastaların da bu benzer etkilere açı olduğu unutulmamalıdır.

Özetle; pandemi sürecinde sporcu sağlığı ile uğraşan sağlık profesyonellerinin asli görevi hem sporcu hem de sporcuyla her türlü paylaşımda bulunan diğer bireylerin sağlığını korumak olmalıdır. Bunun için bilimsel çalışmaların izlenmesi, kanıtların eşliğinde sürekli güncellemelerin yapılması gerekmektedir. 


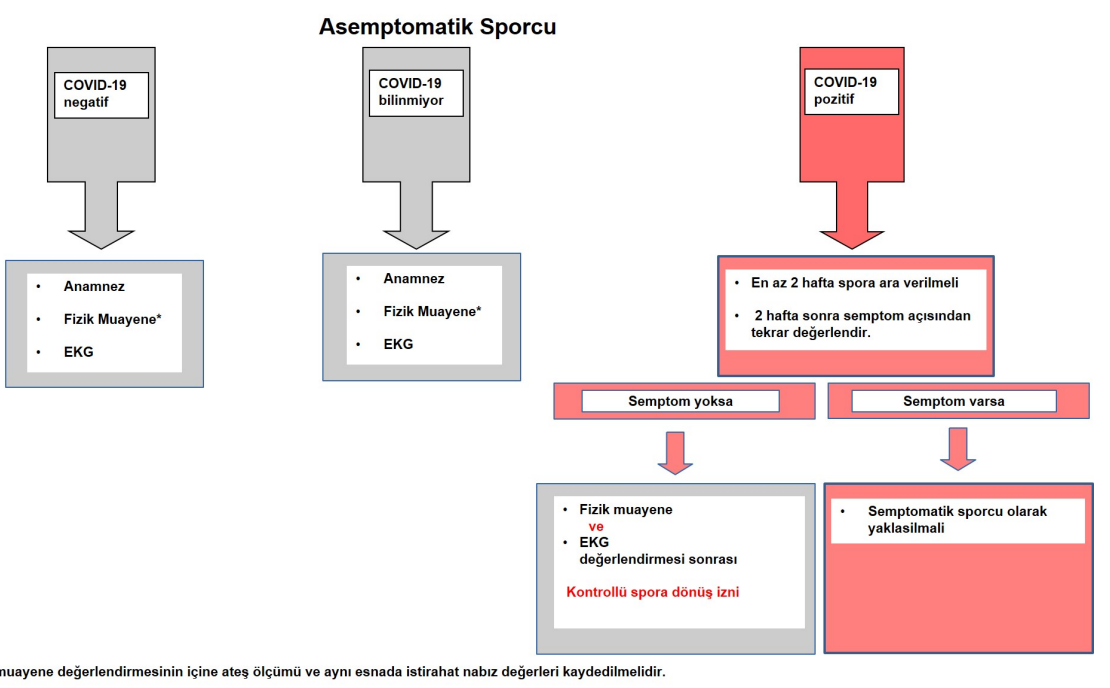

Şekil 1. Asemptomatik sporcuya spora katılım öncesi değerlendirme yaklaşımı
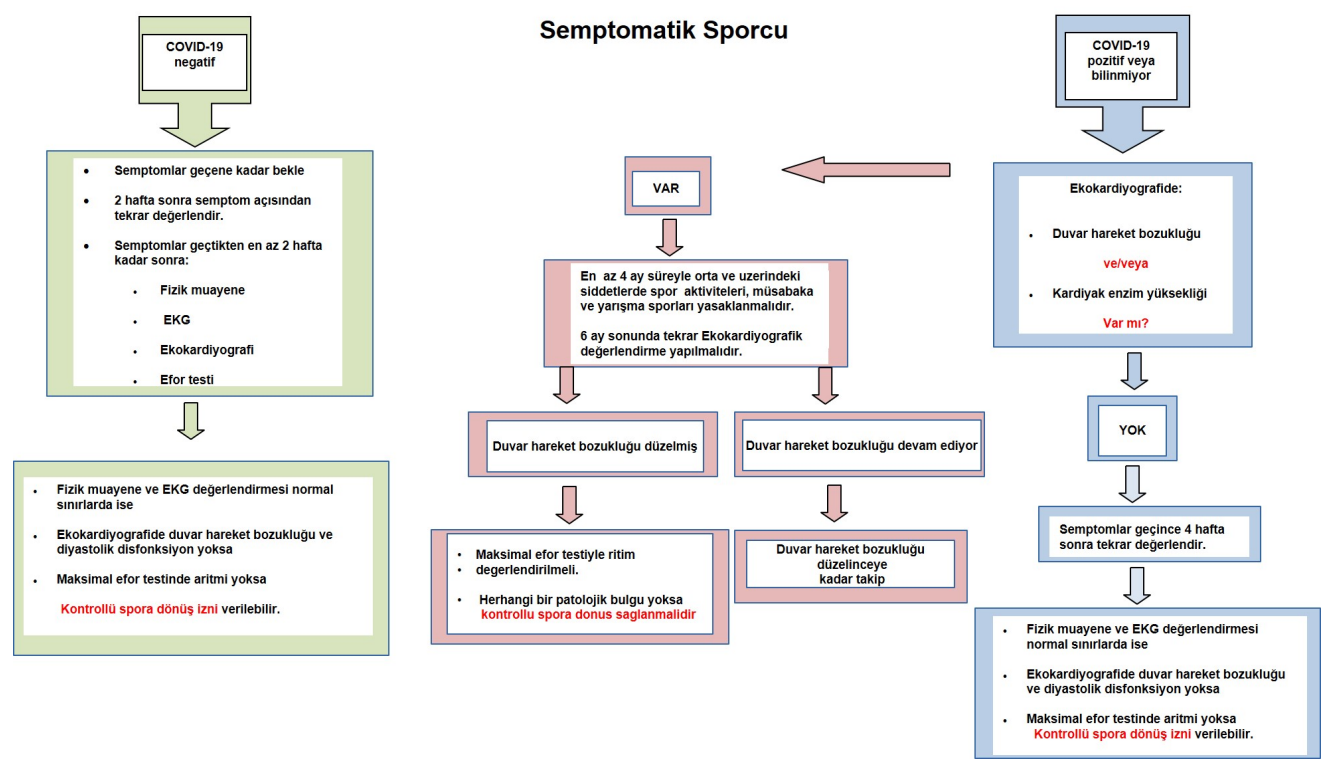

Şekil 2. Semptomatik sporcuya spora dönüş muayenesi yaklaşımı

\section{Acknowledgment}

The authors would like to thank Prof. Karl B. Fields and Prof. Bülent Ülkar for constructive criticism of the manuscript.

\section{Conflict of Interest}

The authors declared no conflicts of interest with respect to the authorship and/or publication of this article.

\section{KAYNAKLAR}

1. Löllgen $H$, Börjesson $M$, Cummiskey J, Bachl N, Debruyne A. The Pre-Participation Examination in Sports: EFSMA Statement on ECG for PreParticipation Examination. Dtsch $Z$ Sportmed. 2015;66: 151-5.

2. Schellhorn $\mathrm{P}$, Klingel $\mathrm{K}$, Burgstahler C. Return to sports after COVID-19 infection. Eur Heart J. 2020; ehaa448. doi: 10.1093/ eurheartj/ ehaa448.

3. Guo T, Fan Y, Chen M, Wu X, Zhang L, He T, et al. Cardiovascular implications of fatal outcomes of patients with coronavirus disease 2019 (COVID-19). 
JAMA Cardiol 2020; doi: 10.1001/ jamacardio.2020.1017.

4. Shi S, Qin M, Shen B,Cai Y, Liu T, Yang F, et al. Association of cardiac injury with mortality in hospitalized patients with COVID-19 in Wuhan, China. JAMA Cardiol. 2020; e200950. doi: 10.1001/jamacardio.2020.0950.

5. Phelan D, Kim JH, Chung EH. A Game plan for the resumption of sport and exercise after Coronavirus disease 2019 (COVID-19) infection [published online ahead of print, 2020 May 13]. JAMA Cardiol. 2020;10.1001/ jamacardio.2020.2136.

6. Dores H, Cardim N. Return to play after COVID-19: a sportcardiologist's view [published online ahead of print, 2020 May 7]. Br J Sports Med. 2020;bjsports2020-102482. doi:10.1136/bjsports-2020-102482.
7. Inciardi RM, Lupi L, Zaccone G, Italia L, Raffo M, Tomasoni D, et al. Cardiac involvement in a patient with Coronavirus disease 2019 (COVID-19) [published online ahead of print, 2020 Mar 27]. JAMA Cardiol. 2020;10.1001/jamacardio.2020.1096. doi:10.1001/jamacardio.2020.1096.

8. Maron BJ, Doerer JJ, Haas TS, Tierney DM, Mueller FO. Sudden deaths in young competitive athletes: analysis of 1866 deaths in the United States, 19802006. Circulation 2009;119:1085-92.

9. Mehra MR, Desai SS, Ruschitzka F, Patel AN. Hydroxychloroquine or chloroquine with or without a macrolid efor treatment of COVID-19: a multinational registry analysis [published online ahead of print, 2020 May 22]. Lancet. 2020;S0140-6736(20)31180-6. doi:10.1016/S0140-6736(20)31180-6. 